\title{
Impact of Pectoral Muscle Values on Clinical Outcomes in Patients With Severe Covid-19 Disease
}

\author{
HAKAN KARDAS $^{1 *}$, MAXIMILIAN THORMANN ${ }^{1 *}$, CAROLINE BÄR $^{1}$, \\ JAZAN OMARI $^{1}$, ANDREAS WIENKE ${ }^{2}$, MACIEJ PECH ${ }^{1}$ and ALEXEY SUROV ${ }^{1}$ \\ ${ }^{1}$ University Clinic for Radiology and Nuclear Medicine, University Hospital Magdeburg, Magdeburg, Germany; \\ ${ }^{2}$ Institute of Medical Epidemiology, Biometry, and Informatics, Martin Luther University, Halle-Wittenberg, Germany
}

\begin{abstract}
Background/Aim: The effect of sarcopenia on patients with severe Covid-19 disease is unknown. We aimed to assess the influence of baseline computed tomography (CT)-based body composition parameters (pectoralis muscle area, pectoralis muscle index, skeletal muscle gauge) on clinical variables in patients with severe Covid-19 disease. Patients and Methods: Chest CT scans of adult patients with confirmed Covid-19 who were hospitalized from March 2020 to May 2021 at a level-one medical center in Germany were retrospectively analyzed. Pectoralis muscle area, pectoralis muscle index and skeletal muscle gauge were measured on the first CT scan after admission. Body composition parameters were assessed for association with clinical variables and 30day mortality. Results: A total of 46 patients were included. None of the body composition parameters was a predictor for 30-day mortality, duration of hospital stay, duration of intensive care unit treatment, or duration of invasive mechanical ventilation. Conclusion: Pectoralis muscle composition parameters in CT chest scans did not predict outcomes in adult patients with severe Covid-19 infection.
\end{abstract}

Sarcopenia is an abnormal body composition defined as the loss of muscle mass, low muscle strength, and impaired muscle quality (1). Screening measures include clinical parameters as well as image-based techniques $(1,2)$. Sarcopenia is common in patients aged 65 years and older and has been related to worse clinical outcome, disability,

This article is freely accessible online.

*These Authors contributed equally to this study.

Correspondence to: Dr. med. Maximilian Thormann, M.A., Clinic for Radiology and Nuclear Medicine, University of Magdeburg, Leipziger Str. 44, 39112 Magdeburg, Germany. E-mail: maximilian.thormann@med.ovgu.de

Key Words: Covid-19, body composition, computed tomography, pectoralis muscle, mortality. and mortality (3-7). Chest scans with either computed tomography (CT) or magnetic resonance imaging are considered the gold-standard for quantitative evaluation of body composition (1). Measurements such as skeletal muscle mass or density can be used as a surrogate marker for sarcopenia and muscle quality (8-10).

The etiology of sarcopenia is manifold and includes nutritional, environmental, behavioral, and medical factors. Sarcopenia is associated with malnutrition, metabolic dysregulation and chronic inflammation, increasing vulnerability of affected adults to various diseases $(9,11)$. Suboptimal protein intake has been associated with sarcopenia, but the diagnosis does not depend on body weight and body mass index (12).

The pectoralis muscle index (PMI) and the pectoralis muscle area (PMA) have been shown to be indicators of sarcopenia and predictors of clinical variables such as length of hospital stay and mortality for multiple diseases $(7,9,13$ 17). In addition, measurements of muscle density on CT scans are regarded as an indicator of muscle quality, reflecting lipid content (10). The skeletal muscle gauge (SMG) integrates both the PMI and muscle density and has been shown to be associated with outcomes in patients with cancer $(18,19)$.

The effect of sarcopenia on patients suffering from Coronavirus 2019 disease (Covid-19) caused by severe acute respiratory syndrome coronavirus 2 is yet unknown. The disease affects mostly elderly people at highest risk for sarcopenia, with age being an independent risk factor for worse outcome $(20,21)$.

Some authors have described that certain body composition parameters can identify unfavorable outcome in patients with Covid-19. For example, a higher level of adipose tissue has been associated with higher rates of hospitalization and mechanical ventilation (22-24). In another study, higher visceral fat area and higher abdominal circumference measured at the lumbar level were correlated with higher rates of transfer to the Intensive Care Unit (ICU) and mechanical ventilation, but mortality was not investigated (25). 
Regarding measurement of skeletal mass, however, the literature results are controversial. For example, in one study, PMI and PMA were associated with length of hospital stay and death in Covid-19 patients (26). However, no strong association between skeletal muscle index (SMI) and clinical variables or mortality was found in another study (27). Density of the pectoralis muscle has been associated with the risk of death in symptomatic patients with Covid-19 (28). Yet no effect of the paraspinal muscle index at the T12 level with clinical outcomes was found in a Chinese cohort of patients hospitalized with Covid-19 disease (29). The literature is still preliminary and shows some variation regarding the muscle region measured and the level where muscle mass is assessed $(9,30)$. However, if an association between muscle mass and clinical outcomes of patients with Covid-19 existed, it might be an important means of triage at hospital admission.

The purpose of the present study was to analyze the effect of pectoralis muscle composition, as measured by PMA, PMI and SMG on CT chest scans, on clinical variables. Length of hospital stay, length of ICU stay, length of invasive mechanical ventilation, and mortality at 30 days were assessed in patients hospitalized with severe Covid-19 infection.

\section{Patients and Methods}

Study population. We retrospectively analyzed a sample of patients admitted to a level-one medical center in Germany with polymerase chain reaction-confirmed symptomatic Covid-19 infection between March 2020 and May 2021. Patients that had undergone a CT chest scan after admission to our clinic were included. Patients were followed-up until discharge or death. The patient cohort included both primary admissions and referrals from other hospitals to the ICU unit. Scans with strong motion artifacts were excluded. For all patients, the length of overall hospital stay, length of ICU stay, length of invasive mechanical ventilation, and mortality at 30 days were noted. Data on clinical variables and mortality were obtained from the hospital system.

Image analysis. All CT scans were obtained on a multidetector CT scanner (Siemens Somatom Definition AS+; Siemens Healthcare, Germany). During the Covid-19 pandemic the scanner was set aside for suspected or confirmed cases. Patients were positioned in supine position. The CT protocol was as follows: Acquisition slice thickness $1 \mathrm{~mm}$ with $5 \mathrm{~mm}$ reconstructions, tube voltage $120 \mathrm{kV}$, automatic tube current modulation, pitch factor 1.2, and collimation $0.6 \mathrm{~mm}$.

We used the first CT scan of patients after hospital admission. All images were assessed in consensus by two experienced radiologists (HK and AS) who were blinded to the clinical course of the patients. Measurements were performed on axial images at the T4 level in the soft tissue window (window of 45 to $250 \mathrm{HU}$ ) on a dedicated workstation (Infinitt PACS, Version 3.0; Infinitt Healthcare, Seoul, Republic of Korea). A line was drawn along the contours of the pectoralis major and minor muscles on both sides and the bilateral areas as determined by the software were added to obtain the PMA (Figure 1). Muscle density was measured for each side on all contrast scans and the mean was calculated. The PMI

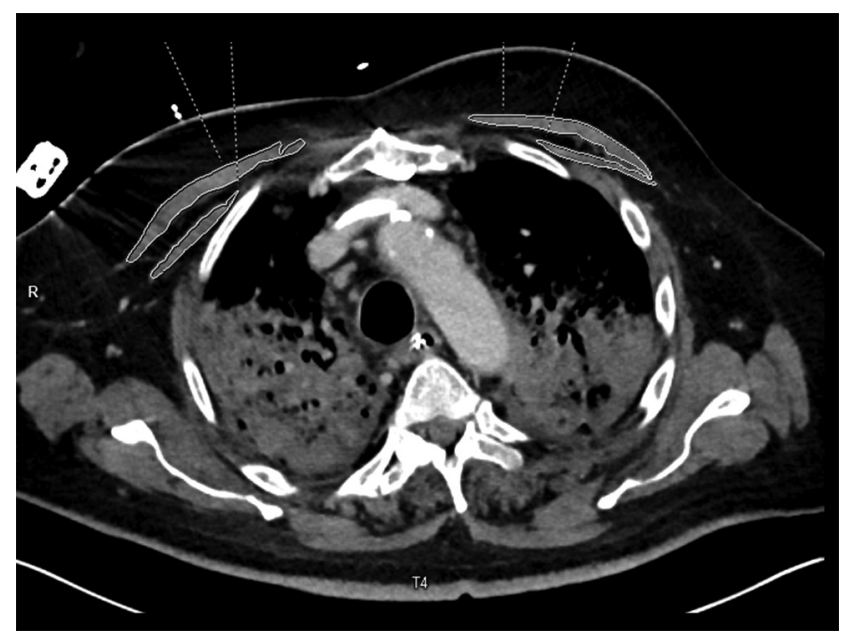

Figure 1. Computed tomography of the thorax of a 67-year-old male patient after contrast injection. The identified muscle parameters were: pectoralis muscle area $18.0 \mathrm{~cm}^{2}$, pectoralis muscle index $5.8 \mathrm{~cm}^{2} / \mathrm{m}^{2}$, muscle density $22.5 \mathrm{HU}$, skeletal muscle gauge $132.3 \mathrm{AU}$. The patient died after 13 days on Intensive Care Unit.

was calculated by dividing the PMA by the patient's height. SMG was calculated multiplying the PMI by the mean muscle density as reported previously (18). SMG units are $\mathrm{cm}^{2} \mathrm{HU} / \mathrm{m}^{2}$ but are reported as arbitrary units (AU) for simplicity. A further variable was calculated dividing the mean density by the PMA.

Statistical analysis. Mean and standard deviation as well as median and interquartile range (IQR) were calculated for continuous variables. To assess the impact of pectoralis muscle composition on clinical variables and mortality, we used a multivariable logistic regression model. Odds ratios are presented together with $95 \%$ confidence intervals $(95 \% \mathrm{CI})$. The resulting $p$-values were interpreted in an exploratory sense.

\section{Results}

Included patients and muscle mass analysis. Of the 74 patients screened, 46 underwent a chest CT scan at admission and were included in the analysis. There were 19 female and 27 male patients. The median age was 64.5 years and median body mass index was $27.3 \mathrm{~kg} / \mathrm{m}^{2}$. Baseline characteristics of patients, PMA, PMI, SMG and density/PMA are summarized in Table I.

Association between muscle parameters and clinical outcomes (Table II). Nineteen patients died within 30 days after admission (41.3\%). Neither PMI nor PMA were strongly associated with 30-day mortality. Likewise, SMG, muscle density and density divided by PMA showed no significant association with mortality. Moreover, neither age nor sex were predictors of death at 30 days in our cohort. 
Table I. Patient characteristics $(n=46)$.

\begin{tabular}{|c|c|c|}
\hline Characteristic & & Value \\
\hline Age, years & Median (range) & $64.5(41-92)$ \\
\hline \multirow[t]{2}{*}{ Gender, n (\%) } & Male & $27(58.7 \%$ \\
\hline & Female & $19(41.3 \%)$ \\
\hline BMI, $\mathrm{kg} / \mathrm{m}^{2}$ & Median (range) & $27.3(20.6-58.5)$ \\
\hline Length of hospital stay, days & Median (range) & $19(1-53)$ \\
\hline \multirow[t]{2}{*}{ ICU stay } & Yes, $\mathrm{n}(\%)$ & $37(80.4 \%)$ \\
\hline & $\begin{array}{l}\text { Median duration } \\
\text { (range), days }\end{array}$ & $11.5(2-53)$ \\
\hline \multirow[t]{2}{*}{ IMV needed } & Yes, n $(\%)$ & $33(71.7 \%)$ \\
\hline & $\begin{array}{l}\text { Median duration } \\
\text { (range), } \mathrm{h}\end{array}$ & $228.5(46-1268)$ \\
\hline Mortality, n (\%) & 30-Day & $19(41.3 \%)$ \\
\hline PMA, $\mathrm{cm}^{2}$ & Median (range) & $22.8(9.0-64.0)$ \\
\hline $\mathrm{PMI}, \mathrm{cm}^{2} / \mathrm{m}^{2}$ & Median (range) & $7.7(3.1-20.9)$ \\
\hline Muscle density, HU & Median (range) & $27.0(4.0-53.5)$ \\
\hline $\mathrm{SMG}, \mathrm{cm}^{2} \mathrm{HU} / \mathrm{m}^{2}$ & Median (range) & $188.8(16.5-612.0)$ \\
\hline Muscle density/PMA, $\mathrm{HU} / \mathrm{cm}^{2}$ & Median (range) & $1.3(0.3-2.9)$ \\
\hline
\end{tabular}

BMI: Body mass index; IMV: invasive mechanical ventilation; PMA: pectoralis muscle area; PMI: pectoralis muscle index; SMG: skeletal muscle gauge.

The median length of hospital stay was 19.0 days, with 37 patients $(80.4 \%)$ being admitted to the ICU for a median of 11.5 days. A total of 33 patients $(71.7 \%)$ received invasive mechanical ventilation for a median duration of 228.5 hours. No association was found between PMA, PMI, SMG or density/PMI for length of hospital stay nor length of ICU stay. No association was found between either variable and length of invasive mechanical ventilation (Table III).

\section{Discussion}

We aimed to evaluate whether muscle-based body composition parameters as measured on chest $\mathrm{CT}$ scans were prognostic factors for mortality and clinical variables such as length of hospital stay and length of invasive mechanical ventilation in hospitalized patients with severe Covid-19 disease. Our study is a comprehensive analysis, associating multiple sarcopenia measures including PMA, PMI, muscle density, and SMG with clinical variables for patients hospitalized with Covid-19. We were not able to find an association between any variable and clinical outcomes nor 30-day mortality in our cohort.

It has been shown that sarcopenia can serve as a predictor of length of hospital stay and mortality in critically ill and trauma patients $(16,31-34)$. In patients with Covid-19, the results are less clear. Muscle area measurements and skeletal mass indices as an indicator for sarcopenia have been conducted at different muscle levels, both at the thoracic and the pelvic level, with conflicting results. In a study by
Table II. Association of pectoralis muscle composition parameters with 30-day mortality.

\begin{tabular}{lccc}
\hline Value & OR & $95 \%$ CI & $p$-Value \\
\hline Age & 0.996 & $0.951-1.042$ & 0.853 \\
Gender (male) & 1.371 & $0.412-4.563$ & 0.607 \\
BMI & 0.990 & $0.922-1.064$ & 0.790 \\
PMA & 1.068 & $0.992-1.150$ & 0.079 \\
PMI & 1.145 & $0.906-1.447$ & 0.257 \\
Muscle density & 0.998 & $0.951-1.047$ & 0.942 \\
SMG & 1.002 & $0.998-1.006$ & 0.309 \\
Muscle density/PMA & 0.689 & $0.250-1.903$ & 0.472 \\
\hline
\end{tabular}

BMI: Body mass index; CI: confidence interval; IMV: invasive mechanical ventilation; OR: odds ratio; PMA: pectoralis muscle area; PMI: pectoralis muscle index; SMG: skeletal muscle gauge.

Schiaffino et al., lower cross-sectional area of paravertebral muscles were positively associated with ICU admission and mortality (30). Skeletal muscle indices were not calculated. In a cohort with 116 patients by Feng et al., no association between paraspinal muscle index at the T12 level and clinical outcomes was found (29). Higher muscle attenuation was associated with reduced critical illness or death, yet only for female patients. Kim et al. calculated the SMI at the T12 level and found that sarcopenia was associated with prolonged hospital stay but not mortality in patients with Covid-19 (35). In their sample, the ICU admission rate was only $8.3 \%$ and mortality was $5.8 \%$. Hocaoglu et al. showed that higher muscle density as measured in non-contrast CT was inversely associated with death in patients with Covid19 (28). However, over $40 \%$ of the cohort of 217 patients were outpatients and PMI was not measured. Furthermore, only major pectoralis muscle was measured. No association with mortality was found for SMI measured below the lung base in a study by Moctezuma-Velázquez et al. (27). Ufuk et al. presented an association between PMA and PMI on negative clinical outcomes such as intubation, length of hospital stay, and mortality (26).

Our cohort differs strongly from those analyzed previously and our patients were more severely affected than in other samples. The median age for our cohort was 65 years, with no patient being younger than 41 years, which is older than the cohort analyzed by Ufuk et al. (median age of 48 years) (26). This may have introduced selection bias, explaining why neither age nor sex were a significant predictor of mortality in our cohort. Overall 30-day mortality was $41 \%$, while it ranged between $5.8 \%$ and $31.8 \%$ in other studies $(26,28,35)$. This is mirrored in the high proportion of our patients treated in the ICU $(80.4 \%)$ and requiring mechanical ventilation $(71.7 \%)$. In the sample by Kim et al., the ICU admission rate was only $8.3 \%$ (35). The percentage of patients receiving mechanical ventilation were $6.6 \%, 11.5 \%$ 
in vivo $36: 375-380(2022)$

Table III. Association of pectoralis muscle composition parameters with clinical variables (univariable model).

\begin{tabular}{|c|c|c|c|c|c|c|c|c|c|}
\hline \multirow[b]{2}{*}{ Parameter } & \multicolumn{3}{|c|}{ Length of hospital stay } & \multicolumn{3}{|c|}{ Length of ICU stay } & \multicolumn{3}{|c|}{ Duration of IMV } \\
\hline & $\beta$ & $95 \% \mathrm{CI}$ & $p$-Value & $\beta$ & $95 \% \mathrm{CI}$ & $p$-Value & $\beta$ & $95 \% \mathrm{CI}$ & $p$-Value \\
\hline Age & -0.009 & $-0.301-0.283$ & 0.953 & -0.241 & $-0.529-0.048$ & 0.099 & -4.918 & $-11.891-2.054$ & 0.162 \\
\hline Gender (male) & 0.242 & $-7.392-7.875$ & 0.949 & 3.559 & $-4.134-11.253$ & 0.356 & 112.450 & $-70.758-295.659$ & 0.223 \\
\hline BMI & 0.003 & $-0.449-0.455$ & 0.989 & 0.300 & $-0.151-0.751$ & 0.187 & 8.289 & $-2.460-19.038$ & 0.127 \\
\hline PMA & -0.165 & $-0.547-0.216$ & 0.387 & 0.246 & $-0.139-0.631$ & 0.204 & 7.323 & $-1.814-16.460$ & 0.113 \\
\hline PMI & -0.792 & $-2.222-0.639$ & 0.271 & 0.610 & $-0.855-2.075$ & 0.406 & 17.603 & $-17.406-52.612$ & 0.316 \\
\hline Density & -0.100 & $-0.406-0.205$ & 0.511 & 0.003 & $-0.310-0.315$ & 0.987 & 0.269 & $-7.220-7.758$ & 0.943 \\
\hline SMG & -0.019 & $-0.043-0.005$ & 0.116 & -0.001 & $-0.026-0.025$ & 0.963 & 0.033 & $-0.573-0.640$ & 0.912 \\
\hline Density/PMA & 2.879 & $-3.408-9.165$ & 0.361 & -2.542 & $-8.955-3.872$ & 0.429 & -77.385 & $-230.534-75.765$ & 0.314 \\
\hline
\end{tabular}

BMI: Body mass index; CI: confidence interval; ICU: Intensive Care Unit; IMV: invasive mechanical ventilation; PMA: pectoralis muscle area; PMI: pectoralis muscle index; SMG: skeletal muscle gauge.

and $21.4 \%$ in the study by Kim et al., Ufuk et al., and Besutti et al., respectively $(22,26,35)$. The study by Moctezuma-Velázquez had a patient cohort with characteristics closer to ours, with an ICU admission rate of $40 \%$ and a mortality of $25 \%$, revealing no association with clinical outcomes (27). A large proportion of our patients (73.9\%) had a hospital stay of more than 10 days, with a median of 19 days, compared with $18.5 \%$ and 7 days for the sample by Ufuk et al. (26). Density values in our sample were measured in contrast CT scans, with other studies using non-contrast images $(28,29)$. Hocaoglu et al. measured the pectoralis muscle density in non-contrast scans, finding cutoff values of 34.1 HU for men and 15.9 HU for women for association with increased mortality (28). Muscle density values are typically higher when measured in the venous phase (36). Nevertheless, our mean density was lower than the cut-off determined by Hocaoglu et al. for the male group, indicating a more critical disease stage.

Sarcopenia may potentially play a role in clinical outcome of patients with Covid-19. Yet we were not able to find such association in patients with severe disease. A possible explanation for this may be found in the nature of the disease, which causes multisystem inflammation and organ failure and subsequent mortality (27). In a cohort already severely affected by the disease in a progressed state, muscle mass at admission may no longer be a good predictor for outcome, as muscle loss is already advanced $(37,38)$.

Our study has several limitations. Firstly, it was a singlecenter study with a small cohort. Not all symptomatic patients with Covid-19 at our center underwent a chest CT scan at admission. Only those with respiratory distress or infiltrates on chest X-ray were further evaluated at the discretion of the attending physician. Thus, patients with symptomatic but mild disease were not analyzed. In the follow-up, only mortality at 30 days was noted. As we evaluated pectoralis muscle composition as a proxy indicator for sarcopenia, the effect of muscle mass at other levels remains unknown. We did not associate our muscle indices with comorbidities.

In conclusion, in patients severely affected by Covid-19, pectoralis muscle composition parameters were not associated with length of hospital or ICU stay, length of mechanical invasive ventilation, or 30-day mortality. Further research is warranted to determine whether muscle indices predict clinical outcome in patients with a less advanced stage of disease.

\section{Conflicts of Interest}

None declared.

\section{Authors' Contributions}

HK: Data analysis, validation and writing original draft. MT: Supervision, validation, investigation, data analysis and writing original draft. CB: Review and editing. JO: validation, review and editing. AW: statistical analysis, review and editing. MP: supervision and writing original draft. AS: supervision, data analysis, review and editing.

\section{References}

1 Cruz-Jentoft AJ, Bahat G, Bauer J, Boirie Y, Bruyère O, Cederholm T, Cooper C, Landi F, Rolland Y, Sayer AA, Schneider SM, Sieber CC, Topinkova E, Vandewoude M, Visser M, Zamboni M and Writing Group for the European Working Group on Sarcopenia in Older People 2 (EWGSOP2), and the Extended Group for EWGSOP2: Sarcopenia: revised European consensus on definition and diagnosis. Age Ageing 48(1): 1631, 2019. PMID: 30312372. DOI: 10.1093/ageing/afy169

2 Liguori I, Russo G, Aran L, Bulli G, Curcio F, Della-Morte D, Gargiulo G, Testa G, Cacciatore F, Bonaduce D and Abete P: Sarcopenia: assessment of disease burden and strategies to improve outcomes. Clin Interv Aging 13: 913-927, 2018. PMID: 29785098. DOI: 10.2147/CIA.S149232 
3 Iannuzzi-Sucich M, Prestwood KM and Kenny AM: Prevalence of sarcopenia and predictors of skeletal muscle mass in healthy, older men and women. J Gerontol A Biol Sci Med Sci 57(12): M772-M777, 2002. PMID: 12456735. DOI: 10.1093/gerona/ 57.12.m772

4 Shachar SS, Williams GR, Muss HB and Nishijima TF: Prognostic value of sarcopenia in adults with solid tumours: A meta-analysis and systematic review. Eur J Cancer 57: 58-67, 2016. PMID: 26882087. DOI: 10.1016/j.ejca.2015.12.030

5 Rossi S, Di Noia V, Tonetti L, Strippoli A, Basso M, Schinzari G, Cassano A, Leone A, Barone C and D'Argento E: Does sarcopenia affect outcome in patients with non-small-cell lung cancer harboring EGFR mutations? Future Oncol 14(10): 919926, 2018. PMID: 29528255. DOI: 10.2217/fon-2017-0499

6 Janssen I: Influence of sarcopenia on the development of physical disability: the Cardiovascular Health Study. J Am Geriatr Soc 54(1): 56-62, 2006. PMID: 16420198. DOI: 10.1111/j.1532-5415.2005.00540.x

7 Surov A and Wienke A: Sarcopenia predicts overall survival in patients with malignant hematological diseases: A meta-analysis Clin Nutr 40(3): 1155-1160, 2021. PMID: 32768316. DOI: 10.1016/j.clnu.2020.07.023

8 Hemke R, Buckless C and Torriani M: Quantitative imaging of body composition. Semin Musculoskelet Radiol 24(4): 375-385, 2020. PMID: 32992366. DOI: 10.1055/s-0040-1708824

9 Ali AM and Kunugi H: Screening for sarcopenia (physical frailty) in the COVID-19 era. Int J Endocrinol 2021: 5563960 , 2021. PMID: 34113379. DOI: $10.1155 / 2021 / 5563960$

10 Bak SH, Kwon SO, Han SS and Kim WJ: Computed tomography-derived area and density of pectoralis muscle associated disease severity and longitudinal changes in chronic obstructive pulmonary disease: a case control study. Respir Res 20(1): 226, 2019. PMID: 31638996. DOI: 10.1186/s12931-0191191-y

11 Welch AA, Hayhoe RPG and Cameron D: The relationships between sarcopenic skeletal muscle loss during ageing and macronutrient metabolism, obesity and onset of diabetes. Proc Nutr Soc 79(1): 158-169, 2020. PMID: 31685055. DOI: $10.1017 /$ S0029665119001150

12 Wannamethee SG and Atkins JL: Muscle loss and obesity: the health implications of sarcopenia and sarcopenic obesity. Proc Nutr Soc 74(4): 405-412, 2015. PMID: 25913270. DOI: 10.1017/S002966511500169X

13 Diaz AA, Martinez CH, Harmouche R, Young TP, McDonald ML, Ross JC, Han ML, Bowler R, Make B, Regan EA, Silverman EK, Crapo J, Boriek AM, Kinney GL, Hokanson JE, Estepar RSJ and Washko GR: Pectoralis muscle area and mortality in smokers without airflow obstruction. Respir Res 19(1): 62, 2018. PMID: 29636050. DOI: 10.1186/s12931-018-0771-6

14 Kinsey CM, San José Estépar R, van der Velden J, Cole BF, Christiani DC and Washko GR: Lower pectoralis muscle area is associated with a worse overall survival in non-small cell lung cancer. Cancer Epidemiol Biomarkers Prev 26(1): 38-43, 2017. PMID: 27197281. DOI: 10.1158/1055-9965.EPI-15-1067

15 Oh J, Song IK, Nam JS, Lee SW, Lee EH and Choi IC: Sarcopenia as a prognostic factor for outcomes after isolated tricuspid valve surgery. J Cardiol 76(6): 585-592, 2020. PMID: 32736904. DOI: $10.1016 /$ j.jjcc.2020.07.010

16 DeAndrade J, Pedersen M, Garcia L and Nau P: Sarcopenia is a risk factor for complications and an independent predictor of hospital length of stay in trauma patients. J Surg Res 221: 161166, 2018. PMID: 29229123. DOI: 10.1016/j.jss.2017.08.018

17 Surov A and Wienke A: Low skeletal muscle mass predicts relevant clinical outcomes in head and neck squamous cell carcinoma. A meta analysis. Ther Adv Med Oncol 13: 17588359211008844, 2021. PMID: 34035838. DOI: $10.1177 / 17588359211008844$

18 Weinberg MS, Shachar SS, Muss HB, Deal AM, Popuri K, Yu H, Nyrop KA, Alston SM and Williams GR: Beyond sarcopenia: Characterization and integration of skeletal muscle quantity and radiodensity in a curable breast cancer population. Breast $\mathrm{J}$ 24(3): 278-284, 2018. PMID: 29139618. DOI: 10.1111/tbj.12952

19 Shachar SS, Deal AM, Weinberg M, Nyrop KA, Williams GR, Nishijima TF, Benbow JM and Muss HB: Skeletal muscle measures as predictors of toxicity, hospitalization, and survival in patients with metastatic breast cancer receiving taxane-based chemotherapy. Clin Cancer Res 23(3): 658-665, 2017. PMID: 27489287. DOI: 10.1158/1078-0432.CCR-16-0940

20 Williamson EJ, Walker AJ, Bhaskaran K, Bacon S, Bates C, Morton CE, Curtis HJ, Mehrkar A, Evans D, Inglesby P, Cockburn J, McDonald HI, MacKenna B, Tomlinson L, Douglas IJ, Rentsch CT, Mathur R, Wong AYS, Grieve R, Harrison D, Forbes H, Schultze A, Croker R, Parry J, Hester F, Harper S, Perera R, Evans SJW, Smeeth L and Goldacre B: Factors associated with COVID-19-related death using OpenSAFELY. Nature 584(7821): 430-436, 2020. PMID: 32640463. DOI: $10.1038 / \mathrm{s} 41586-020-2521-4$

21 Risk for COVID-19 infection, hospitalization, and death by age group I CDC. Available at: https://www.cdc.gov/coronavirus/ 2019-ncov/covid-data/investigations-discovery/hospitalizationdeath-by-age.html [Last accessed on June 14 $4^{\text {th }}, 2021$ ]

22 Besutti G, Pellegrini M, Ottone M, Cantini M, Milic J, Bonelli E, Dolci G, Cassone G, Ligabue G, Spaggiari L, Pattacini P, Fasano T, Canovi S, Massari M, Salvarani C, Guaraldi G, Rossi PG and Reggio Emilia COVID-19 Working Group: The impact of chest CT body composition parameters on clinical outcomes in COVID-19 patients. PLoS One 16(5): e0251768, 2021. PMID: 33989341. DOI: 10.1371/journal.pone.0251768

23 Viddeleer AR, Raaphorst J, Min M, Beenen LFM, Scheerder MJ, Vlaar APJ, Amsterdam UMC COVID-19 Biobank, Beudel M and Hemke R: Intramuscular adipose tissue at level Th12 is associated with survival in COVID-19. J Cachexia Sarcopenia Muscle 12(3): 823-827, 2021. PMID: 33939338. DOI: 10.1002/ jcsm.12696

24 Watanabe M, Caruso D, Tuccinardi D, Risi R, Zerunian M, Polici M, Pucciarelli F, Tarallo M, Strigari L, Manfrini S, Mariani S, Basciani S, Lubrano C, Laghi A and Gnessi L: Visceral fat shows the strongest association with the need of intensive care in patients with COVID-19. Metabolism 111: 154319, 2020. PMID: 32712222. DOI: 10.1016/j.metabol. 2020.154319

25 Petersen A, Bressem K, Albrecht J, Thieß HM, Vahldiek J, Hamm B, Makowski MR, Niehues A, Niehues SM and Adams LC: The role of visceral adiposity in the severity of COVID-19: Highlights from a unicenter cross-sectional pilot study in Germany. Metabolism 110: 154317, 2020. PMID: 32673651. DOI: $10.1016 /$ j.metabol.2020.154317

26 Ufuk F, Demirci M, Sagtas E, Akbudak IH, Ugurlu E and Sari T: The prognostic value of pneumonia severity score and pectoralis muscle Area on chest CT in adult COVID-19 patients. 
Eur J Radiol 131: 109271, 2020. PMID: 32942198. DOI: 10.1016/j.ejrad.2020.109271

27 Moctezuma-Velázquez P, Miranda-Zazueta G, Ortiz-Brizuela E, González-Lara MF, Tamez-Torres KM, Román-Montes CM, Díaz-Mejía BA, Pérez-García E, Villanueva-Reza M, TovarMéndez VH, Medrano-Borromeo C, Martínez-Valenzuela A, Jandete-Medina MÁ, Martínez-Guerra BA, Uscanga-Domínguez L, Sifuentes-Osornio J, Ponce-de-León A, Olivas-Martinez A and Moctezuma-Velázquez C: Low thoracic skeletal muscle area is not associated with negative outcomes in patients with COVID-19. Am J Phys Med Rehabil 100(5): 413-418, 2021. PMID: 33587451. DOI: 10.1097/PHM.0000000000001716

28 Hocaoglu E, Ors S, Yildiz O and Inci E: Correlation of pectoralis muscle volume and density with severity of COVID-19 pneumonia in adults. Acad Radiol 28(2): 166-172, 2021. PMID: 33281041. DOI: 10.1016/j.acra.2020.11.017

29 Feng Z, Zhao H, Kang W, Liu Q, Wu J, Bragazzi NL, Ma X, Wang $W$ and Rong P: Association of paraspinal muscle measurements on chest computed tomography with clinical outcomes in patients with severe Coronavirus disease 2019. J Gerontol A Biol Sci Med Sci 76(3): e78-e84, 2021. PMID: 33355656. DOI: $10.1093 /$ gerona/glaa3 17

30 Schiaffino S, Albano D, Cozzi A, Messina C, Arioli R, Bnà C, Bruno A, Carbonaro LA, Carriero A, Carriero S, Danna PSC, D’Ascoli E, De Berardinis C, Della Pepa G, Falaschi Z, Gitto S, Malavazos AE, Mauri G, Monfardini L, Paschè A, Rizzati R, Secchi F, Vanzulli A, Tombini V, Vicentin I, Zagaria D, Sardanelli F and Sconfienza LM: CT-derived chest muscle metrics for outcome prediction in patients with COVID-19. Radiology 300(2): E328-E336, 2021. PMID: 33724065. DOI: 10.1148/radiol.2021204141

31 Ji Y, Cheng B, Xu Z, Ye H, Lu W, Luo X, Fu S and Fang X: Impact of sarcopenic obesity on 30-day mortality in critically ill patients with intra-abdominal sepsis. J Crit Care 46: 50-54, 2018. PMID: 29677586. DOI: 10.1016/j.jcrc.2018.03.019

32 Joyce PR, O'Dempsey R, Kirby G and Anstey C: A retrospective observational study of sarcopenia and outcomes in critically ill patients. Anaesth Intensive Care 48(3): 229-235, 2020. PMID: 32486830. DOI: $10.1177 / 0310057 X 20922234$
33 Kou HW, Yeh CH, Tsai HI, Hsu CC, Hsieh YC, Chen WT, Cheng HT, Yu MC and Lee CW: Sarcopenia is an effective predictor of difficult-to-wean and mortality among critically ill surgical patients. PLoS One 14(8): e0220699, 2019. PMID: 31393937. DOI: 10.1371/journal.pone.0220699

34 Ng CC, Lee ZY, Chan WY, Jamaluddin MF, Tan LJ, Sitaram PN, Ruslan SR and Hasan MS: Low muscularity as assessed by abdominal computed tomography on intensive care unit admission is associated with mortality in a critically ill Asian population. JPEN J Parenter Enteral Nutr 44(3): 425-433, 2020. PMID: 31173666. DOI: 10.1002/jpen.1666

35 Kim JW, Yoon JS, Kim EJ, Hong HL, Kwon HH, Jung CY, Kim KC, Sung YS, Park SH, Kim SK and Choe JY: Prognostic implication of baseline sarcopenia for length of hospital stay and survival in patients with Coronavirus disease 2019. J Gerontol A Biol Sci Med Sci 76(8): e110-e116, 2021. PMID: 33780535. DOI: 10.1093/gerona/glab085

36 van Vugt JLA, Coebergh van den Braak RRJ, Schippers HJW, Veen KM, Levolger S, de Bruin RWF, Koek M, Niessen WJ, IJzermans JNM and Willemsen FEJA: Contrast-enhancement influences skeletal muscle density, but not skeletal muscle mass, measurements on computed tomography. Clin Nutr 37(5): 17071714, 2018. PMID: 28743427. DOI: 10.1016/j.clnu.2017.07.007

37 Baggerman MR, van Dijk DPJ, Winkens B, van Gassel RJJ, Bol ME, Schnabel RM, Bakers FC, Olde Damink SWM and van de Poll MCG: Muscle wasting associated co-morbidities, rather than sarcopenia are risk factors for hospital mortality in critical illness. J Crit Care 56: 31-36, 2020. PMID: 31805466. DOI: 10.1016/j.jcrc.2019.11.016

38 Ju S, Choi SM, Park YS, Lee CH, Lee SM, Yoo CG, Kim YW, Han SK and Lee J: Rapid muscle loss negatively impacts survival in critically ill patients with cirrhosis. J Intensive Care Med 35(7): 663-671, 2020. PMID: 29742956. DOI: 10.1177/ 0885066618775706

Received September 21, 2021

Revised October 31, 2021

Accepted November 13, 2021 